\title{
TOBRUK UNIVERSITY GRADING SYSTEM FOR COLLEGE OF NURSING VERSION 2 IN TOBRUK, LIBYA
}

\author{
James Neil B. Mendoza ${ }^{1}$, Dorothy G. Buhat-Mendoza ${ }^{2}$ and Crisola G. Tan ${ }^{3}$ \\ ${ }^{1}$ Lecturer - Computer Subjects, College of Nursing, Tobruk University, Libya \\ ${ }^{2}$ Lecturer - Nursing Subjects, College of Nursing, Tobruk University, Libya \\ ${ }^{3}$ Assistant Lecturer - Computer Subjects, College of Arts and Sciences, Tobruk \\ University, Libya
}

\begin{abstract}
Grading is the process of applying standardized measurements of varying levels of achievement in a course. Grading measures the students' academic capability. Database Management System plays a vital role in recording information of any kind. Grades or students mark can be recorded in a repository. As the student performs, all academic measures were recorded into the database system, over the years it accumulated to a large amount. Recorded data were useful in educational data mining as unknown and hidden data patterns of all courses, database grading system of Tobruk University College of Nursing known as TUCON-GSv2 a successor to OMUCON-GSv1 can be used to extract and analyze this data. Database management system methods and implementations like recording of data in tables, queries and report, using Visual Basic as front end for the system and Microsoft excel as report, the system and the research performs according to what is needed and generated valuable findings. Overall the TUCONGSv2 can produce helpful and meaningful data as it promoted simple educational data mining. The system serves as a vital element in the improvement of quality education for the College. The main purpose of this study is to document and present the performance and operation of the system from inception up to its present form, solve the report generation challenge for retaining the old format integrated in the new system and for the promotion of DBMS, Computer Science and Nursing Education in Tobruk, Libya.
\end{abstract}

\section{KEYWORDS}

Data Mining, DBMS, computer science, academic performance, Nursing Informatics

\section{INTRODUCTION}

Grading is defined in education as the process of applying standardized measurements of varying levels of achievement in a course[1].In most countries, all grades from all current classes are averaged to create a grade point average (GPA) for the marking period or a semester for Colleges and Universities. The GPA is calculated by taking the number of grade points a student earned in a given period of time [2].Academic performance suggests how well a student accomplished tasks and studies [3]. Student retention and performance are deemed as important issues for both educators and students [4].

Academic performance can be measured by different assessments like class test marks, lab performance, assignment, quiz and attendance [5]. The accumulated marks will then be averaged. The GPA was then evaluated in the following adjectival rating in Libya, 85-100\% Perfect or Excellent, 75-84\% Very Good, 65-74\% Good, 50-64\% Accepted and 0-49 as Failed/Unsatisfactory [6]. In Tobruk University College of Nursing (formerly Omar Al Mukhtar 
University), assessment per class were manually recorded by the faculty members in what they called a mark list. The mark list is then given to the registrar's office for encoding, previously in Microsoft Excel worksheet that serves as their educational database. Eventually it was transformed into OMUCON-GSv1created by the author, it utilizes student database grading system created with Visual Basic as front end and with MS-Access as its back end support, store students' personal information, educational performance for every subject with semesters and school year divided into several queries [7].Implemented since academic year of 2010-2011, data storage and retrieval were made easy. It has undergone several changes in terms of operational aspects. In 2014 the author uses the system for a data mining research [7].

Database management system is a suite of computer software providing interface between users and databases [8]. Database has been explored and performed for many years, known as a collection of structured information about a subject or for a particular purpose [9]. The amount of data stored in educational database increases rapidly over the years [10] and so is the amount of data maintained in any electronic format increased noticeably, as the amount of information doubles so was the database at a greater pace[11]. Data was recorded as it was believed to be a source of potentially useful information [12]. Data in every bit has a lot of concealed information [13], as Collegiate education evolves so is the need to execute database management. Data mining on the other hand is a technology used to extract meaningful information and to develop significant relationship among variables stored in a data set $[10,11]$. Currently Tobruk University College of Nursing Grading System version 2 or TUCON-GSv2 is the database system being used by the college. A successor to the OMUCON-GSv2 after the Tobruk branch of Omar Al Mukhtar University separated from the main campus in A.Y. 20152016 [14]. In this research, the proponent presented a Grading System custom built for the use of the College of Nursing. Exploring the uses and benefits of the system the study aimed to provide worthy educational data to the Institution in aide of improving educational competence and academic performance as a whole. The study also promotes the use of Database Management System to handle educational records.

\section{MATERIALS AND METHODS}

\subsection{System and Data Presentation}

The system will be presented using existing data sets of Academic performance by the students in the academic semester and the whole school year as well. Simple database management element approach and implementation was used to extract, analyze and present the data in useful format. The student database grading system TUCON-GSv2 was used to perform database management and statistical treatment of data. Collected data and system operation were organized into figures to permit ease of analysis. All data measures and its presentation were performed and generated by the software application TUCON-GSv2. Report generation codes of the actual system was also used.

\subsection{Study Population}

The study population consisted of 7 batches of students were all records are in the current system. Batch 2011, historically the $4^{\text {th }}$ batch of students who entered the College of Nursing on Academic Year (AY) 2010-2011, and the pioneering batch to be entered in the system as $1^{\text {st }}$ year students' in the College. Respectively Batch 2012 up to Batch 2017was students' who entered the college in AY 2011-2012 until AY 2016-2017. Population was selected based on their student number hence named Batch number. Additionally older batches 2008, 2009 and 2010 were also in the system albeit with partial records in the old and in the new system. 


\subsection{Programming Technique}

The proponent utilized the $4^{\text {th }}$ generation technique (4GT) in the development of the Grading System based on NPL or Non- Procedural Language techniques. Depending on the specifications, the 4GT employ various tools for the automatic generation of source codes [15]. It is the vital tool which uses the non-procedural language for report generation, database query, data manipulation, user interface, code generation, spread sheet capabilities and more.

\subsection{Software Application}

Tobruk University College of Nursing Grading System Version 2 or TUCON-GSv2 is a software application that stores student information, subjects offered and academic records. The system was utilized to perform data measurement and presentation. The system was created using Visual Basic version 6 as front end, Microsoft Access for back end and Microsoft Excel for report generation.

\subsection{Clinical Instructor}

A clinical instructor co-authored the research to prove the integrity of the courses offered, operational aspect of the Nursing College and evaluation of data. Computational process of major nursing subjects especially the marks for Related Nursing Education (nursing laboratory) and Intensive Nursing Practicum (hospital base). The system is intended to benefit the Nursing College of Tobruk University, clinical instructor and faculty member, and nursing students.

\section{The Grading System}

Student report were recorded and extracted in TUCON-GSv2, figures will be used to present the actual screen shot of the system during its operation. Historical operation of the old system until the latest version will also be presented.

\subsection{The old system}

Prior to the OMUCON-GSv1, the College of Nursing uses Microsoft Excel to record and report the result of the academic performance of the students. Several worksheets' was used to represent every subject or course for a given semester or school year (the College started a yearly program for nursing instead of a semester). Another worksheet was used to present the result for all courses, GPA and rating, all worksheet combined will compose the workbook for 1 year level. Records and fields were mostly written in Arabic Language.

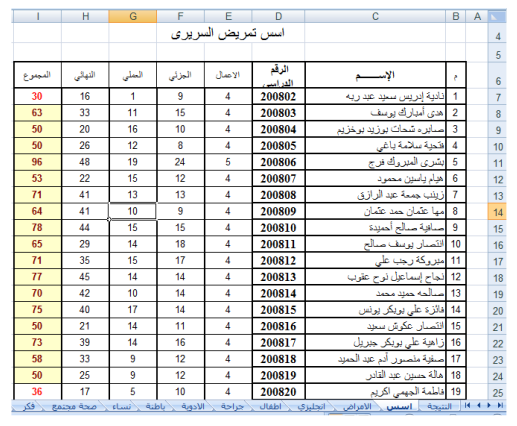

Figure 1: Worksheet for one course 
As shown in Figure 1, the encoder will use this Excel worksheet to input the academic performance of the students after getting the manually written mark list from the faculty member. Every course uses a standard scoring although some faculty chooses to add or combine some criteria. Basically there are two possible course or subject, one with laboratory and one without laboratory. Lecture subjects without laboratory consist of class performance and major exam (midterm and final). Subjects with laboratory composed of class performance, laboratory exam and major exam. Passing mark is 50 and above for all subjects, although when the program shift from yearly to semester, major nursing subjects passing mark was set to 60 or higher.

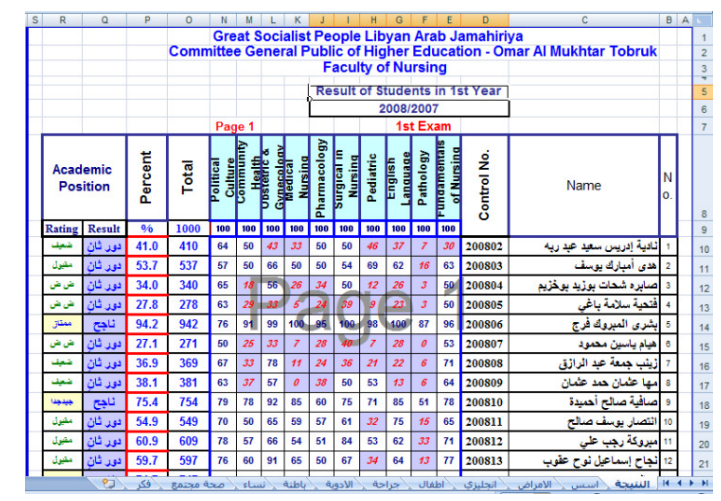

Figure 2: $1^{\text {st }}$ Assessment Report: Final Result, Total, GPA and Rating

After encoding into individual course worksheet, another worksheet will present the accumulated marks of all students for every course, the aggregation of the mark as Total, the average as Percent equivalent or GPA and academic position as evaluation rating. Academic position is divided into two, result and rating. Result is either the students passed if they passed all their subjects or take $2^{\text {nd }}$ assessment equivalent to a removal exam at a later time. Rating is when GPA was evaluated using Libya's standard rating, 85-100\% Perfect or Excellent, 75-84\% Very Good, 65-74\% Good, 50-64\% Accepted and 0-49 as Failed/Unsatisfactory. Subjects and the rest of the column fields were translated to English language for reference only.

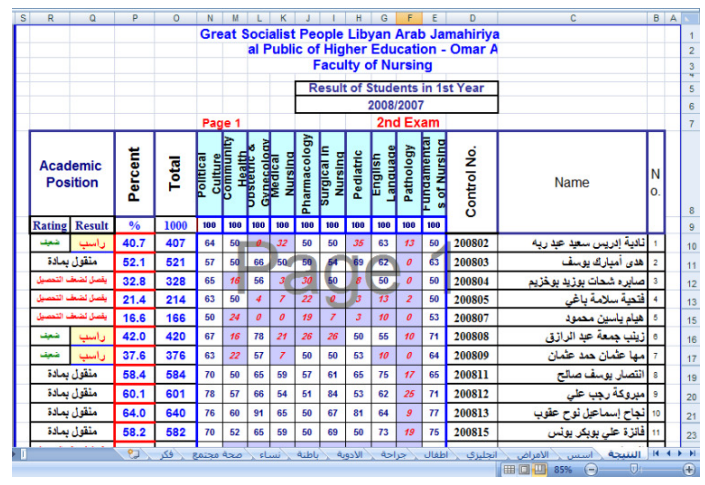

Figure 3: $2^{\text {nd }}$ Assessment Report: Final Result, Total, GPA and Rating

There are two reports that the registrar prints after the exam period (Figure 1, Figure 2). The $1^{\text {st }}$ assessment report was produced after the final exam and the $2^{\text {nd }}$ assessment report or the result after the students have taken the removal exam. The difference between the two reports was that 
in $2^{\text {nd }}$ assessment there will be 6 possible results, Passed if they passed all their courses, Passed with 1 carrier subject, Passed with 2 carrier subjects, Repeat the School level, Failed/ change program, Reported absent/not attending classes/exam. Those who passed all subjects in the $1^{\text {st }}$ assessment report will not be included in the $2^{\text {nd }}$ assessment report. The student can be promoted to the next year level even if they fail 1 or 2 courses, the failed courses will be loaded to the list of subjects the following school year. If they fail 3 or more courses then they have to repeat the school level until they passed all the remaining subjects they failed. If the GPA of students is less than $35 \%$, they will be advice to change program and will not be accepted in the college again.

\subsection{OMUCON-GSv1}

In 2009, the College of Nursing changes their program from yearly to semester period. The course outline was improved, more subjects were added, and passing mark for nursing subjects was increased from 50 to 60 . As the need for an organized database increased in 2010 the management of CON suggested the creation of a Grading System. The author created the database in Microsoft Access, using Visual Basic for User Interface. Eventually after a series of test for report, the author decided to use Microsoft Excel for report generation called by a procedure in Visual Basic.

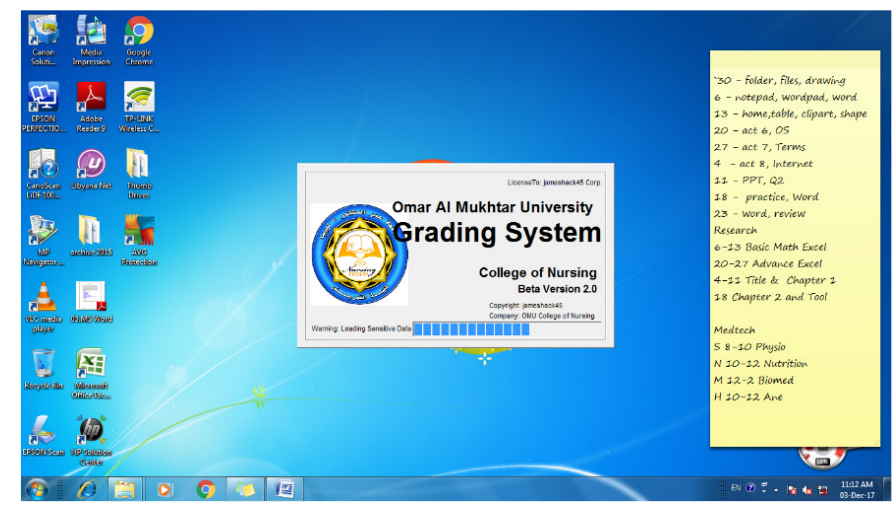

Figure 4: Modified Splash Screen of OMUCON-GSv1 (Version 2)

Figure 4 shows the splash screen of OMUCON-GSv1, the last and latest design while the College of Nursing is still under Omar Al-Mukhtar University. Version 1 and version 2 of OMUCON-GS is pretty much the same albeit different logo and some update in the database were introduced.

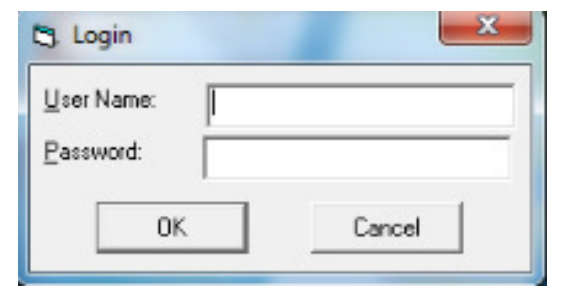

Figure 5: Login Module for OMUCON-GSv1

In figure 5, the username and password login was displayed. Only the registrar, exam supervisor and encoder were entrusted the security login to prevent unauthorized access. 
International Journal of Database Management Systems ( IJDMS ) Vol.9, No.6, December 2017

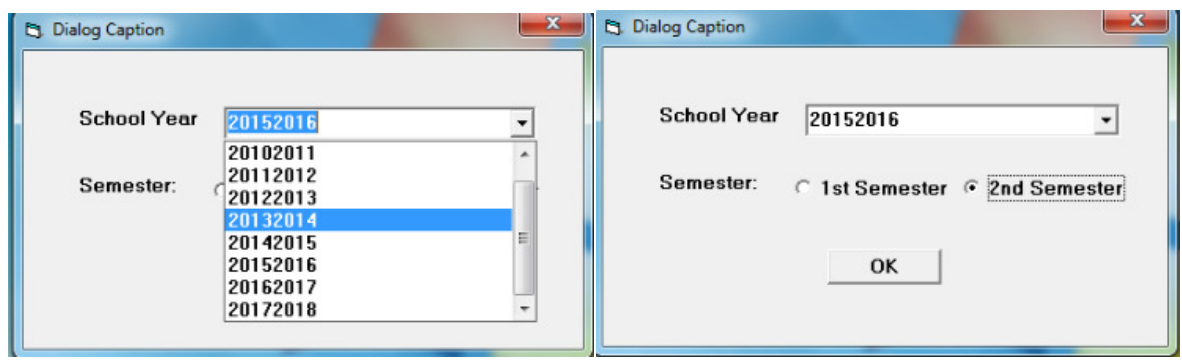

Figure 6: School Year and Semester Selection for OMUCON-GSv1

Since the inception of the semester program, the Grading system was designed to fit the school year and semester division (Figure 6). First the operator must choose the school year to generate then choose which semester, then click Ok button to proceed to the next module.

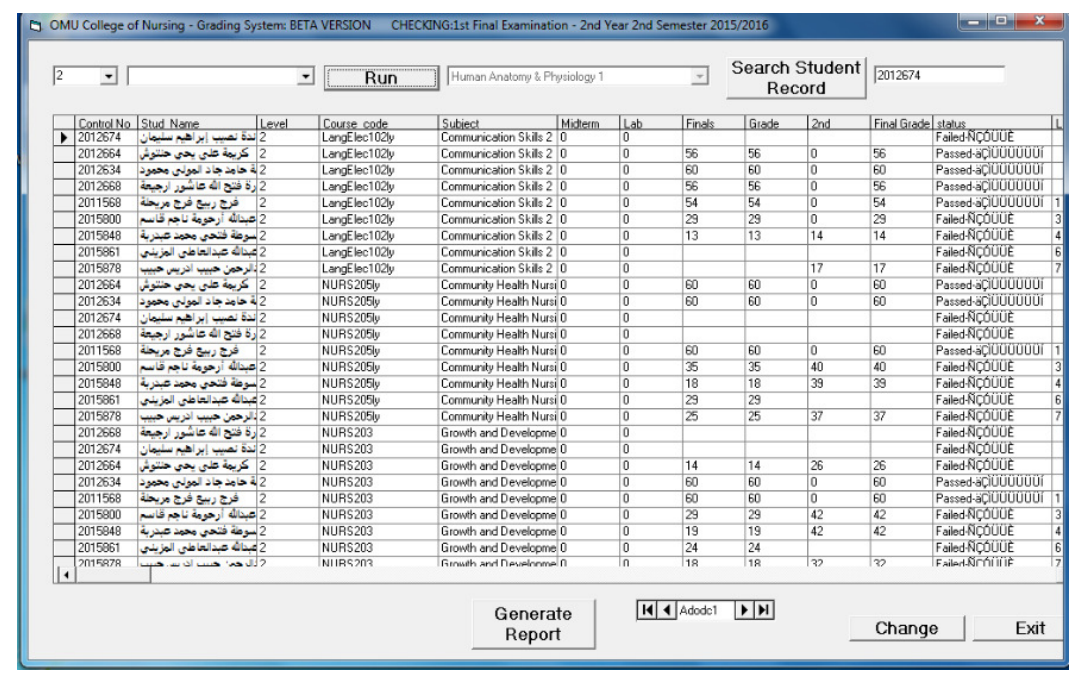

Figure 7: Main Module of OMUCON-GSv1

The main module of OMUCON-GSv1 as shown in figure 7 lets the user to choose the school year and the department if necessary in the combo box above. A search button for course and student records filtered by their student number for accurate posting is also included. The Generate Report button will be used for generating the result in a spreadsheet. Change button to choose another school year and semester. Exit button to close the program. 
International Journal of Database Management Systems ( IJDMS ) Vol.9, No.6, December 2017

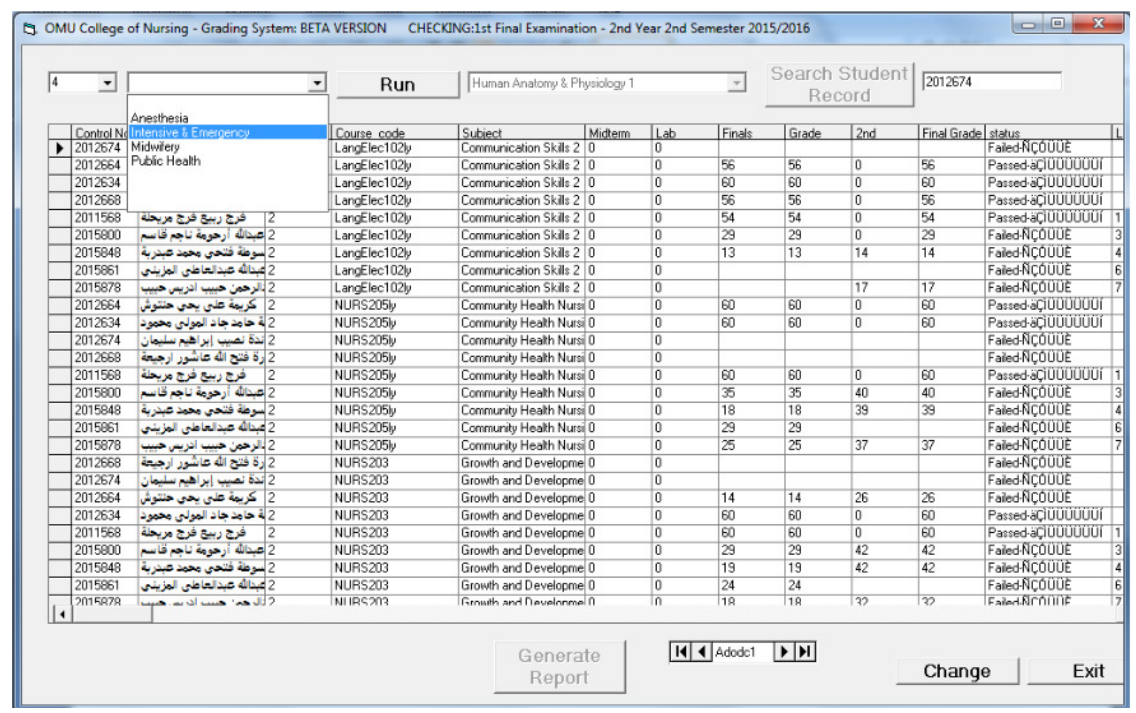

Figure 8: Operating the Main Module of OMUCON-GSv1

In order for the report to be generated, the year level must be selected and the department if the year level is $3^{\text {rd }}$ or $4^{\text {th }}$ year level. Previous department includes Anesthesia, Intensive and Emergency, Midwifery and Public Health nursing. Generate Report button is disabled by default and can only be activated when proper year level is selected.

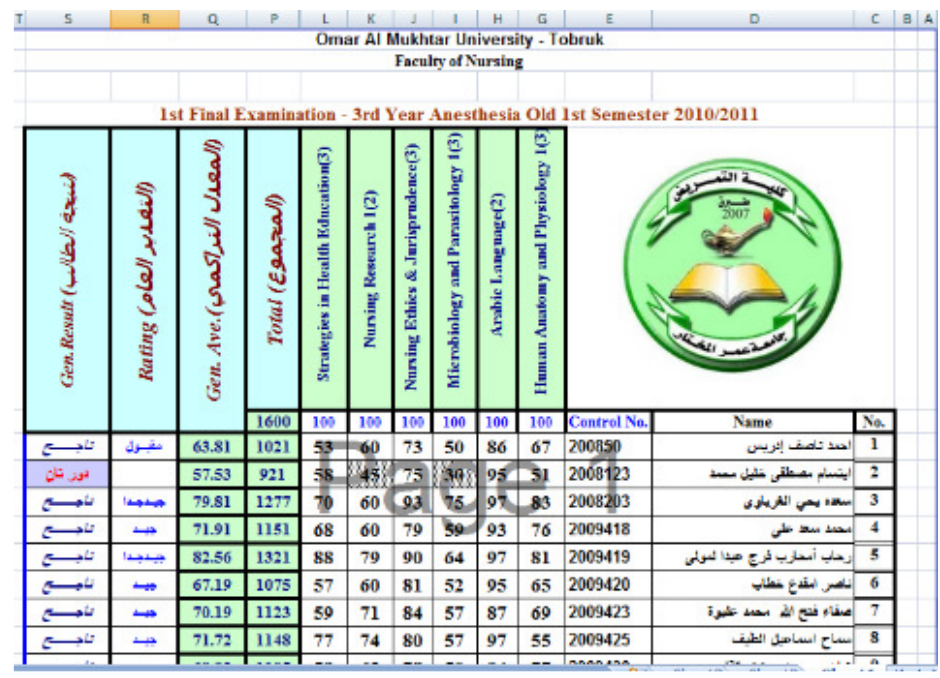

Figure 9: Report Generated by OMUCON-GSv1

The result will be generated in a spreadsheet as shown in figure 9, the worksheet were automatically locked to prevent alteration. 


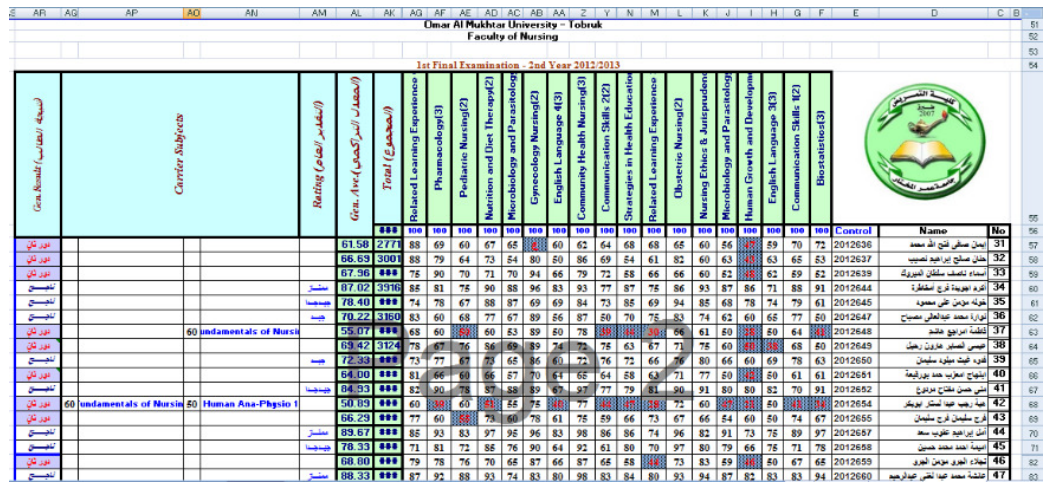

Figure 10: Report Generated by OMUCON-GSv1 (improved color coding)

Early design of the report was a little bit plain in terms of appearance, the exam supervisor suggested changes in the color coding were passing marks will appear in black text and white background cell, failing mark will be displayed in red text and blue shaded background as shown in Figure 10. Unlike the original worksheet for the College's grading system, the evaluation rating will only be given if the student passed all their subjects. Carrier subjects were placed after the general average or GPA thus suggesting it's not included in the computation of Total and General Average but counted as a course. Since the College is an Arabic institution, reports were posted in a right to left format. The name and evaluation remained written in Arabic language.

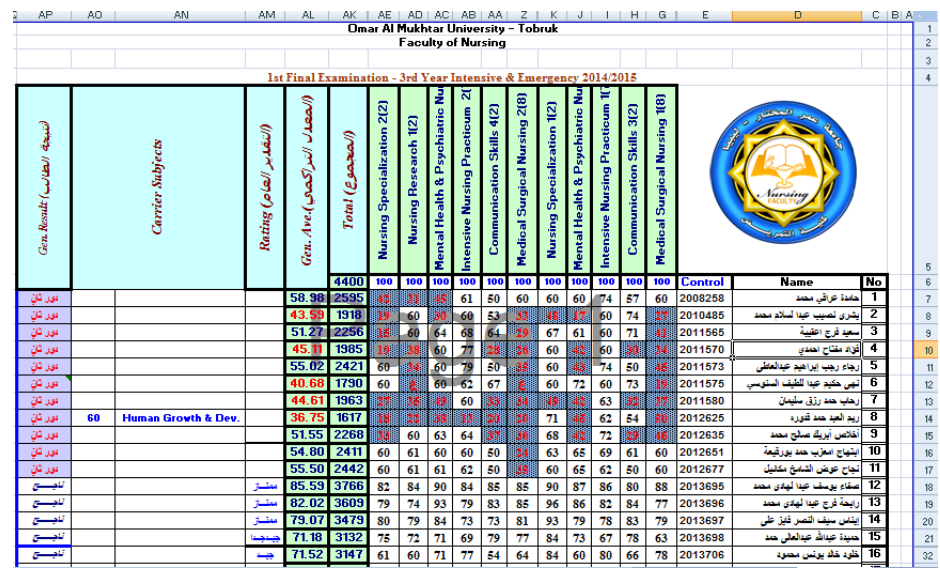

Figure 11: Report Generated by OMUCON-GSv1 (Version 2)

After a couple of years of software implementation, the University changes its official logo and courses offered, thus minor changes in design were added to the system (Figure 11). Similar with the first grading system, the report to be submitted by the registrar included the result of the $1^{\text {st }}$ final exam and $2^{\text {nd }}$ final exam. Students who passed all subjects on $1^{\text {st }}$ assessment will not be included in the report of the $2^{\text {nd }}$ assessment.

\subsection{TUCON-GSv2}

In the middle of school year 2015-2016 the Colleges in the Tobruk Branch of Omar Al-Mukhtar University separated from the main campus thus they establish Tobruk University. Changes in the logo, school and system operation prompted the author to redesign the system albeit with minimal configuration. 
International Journal of Database Management Systems ( IJDMS ) Vol.9, No.6, December 2017

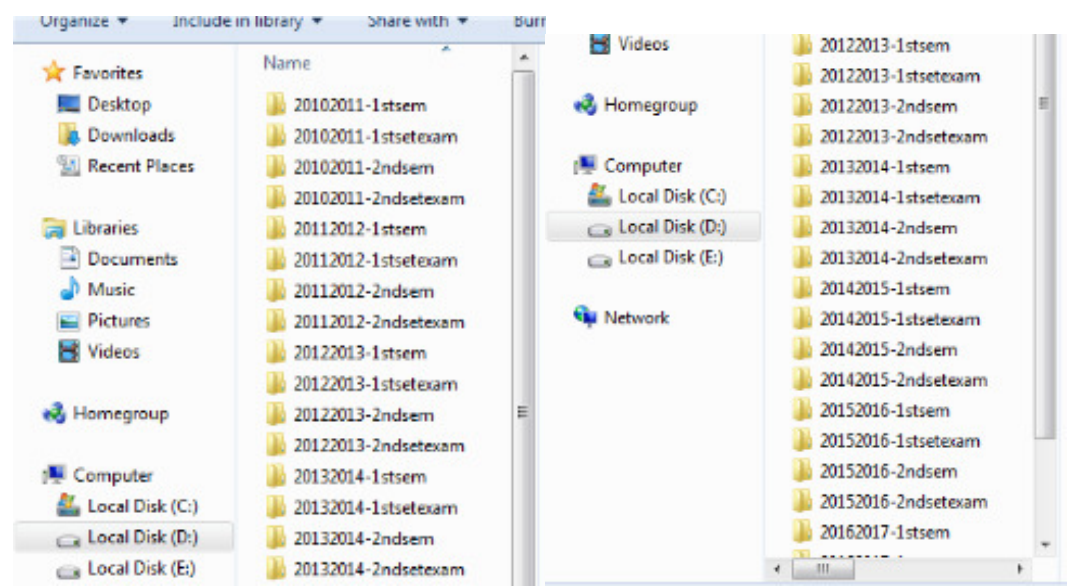

Figure 12: Folder ofReport Generated by OMUCON-GSv1 and TUCON-GSv2

TUCON-GSv2 is an update of OMUCON-GSv1 and the records and report produced by the latter were integrated to the new system. The same database were still being used for the new system, the report were saved as a worksheet file and sorted according to school year and semester as seen in figure 12.

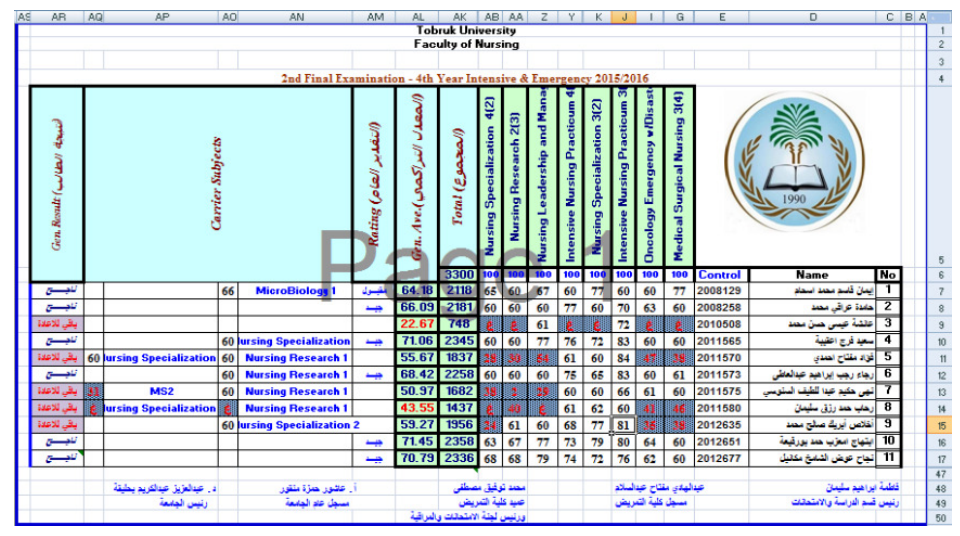

Figure 13: Report Generated by TUCON-GSv2

Report generated by TUCON-GSv2 list the students name, control number, subjects taken, total, Gen. average or GPA, evaluation rating if they passed all subjects, Carrier or loading subjects retaken if present and general result or status. 
International Journal of Database Management Systems ( IJDMS ) Vol.9, No.6, December 2017

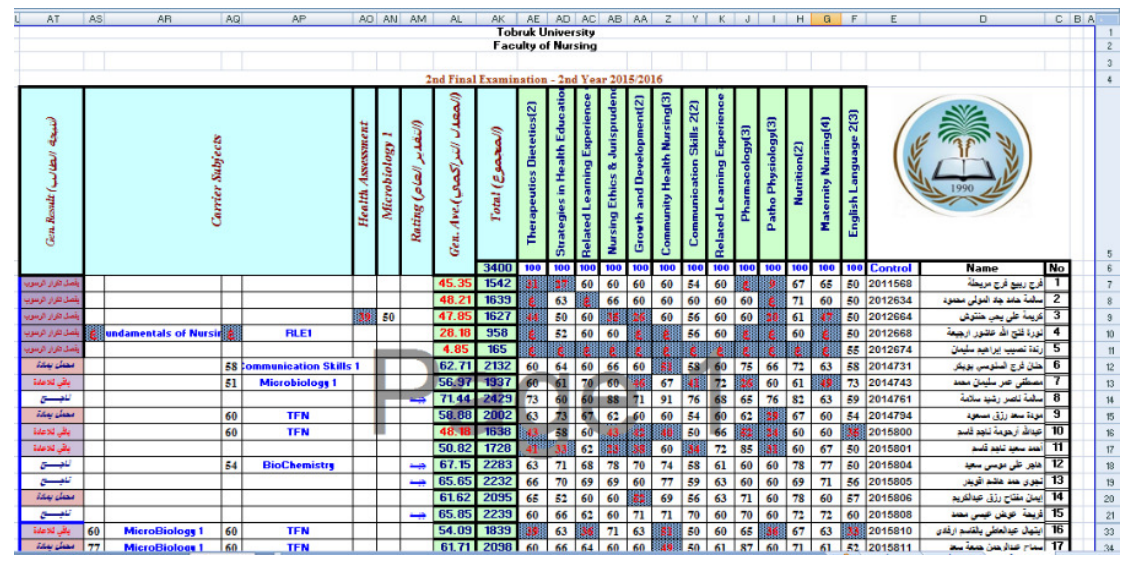

Figure 14: Report Generated by TUCON-GSv2 after the $2^{\text {nd }}$ Final Examination

Sometimes transferee students from another colleges were subjects offered was taken on a different school year, it will be added as a special subject for the students in a different column after the students rating. " $\dot{\varnothing}$ " is an Arabic word meaning absent, if the student did not take the final exam, they will be marked absent from the course, this mark is equivalent to 0 when GPA was computed.

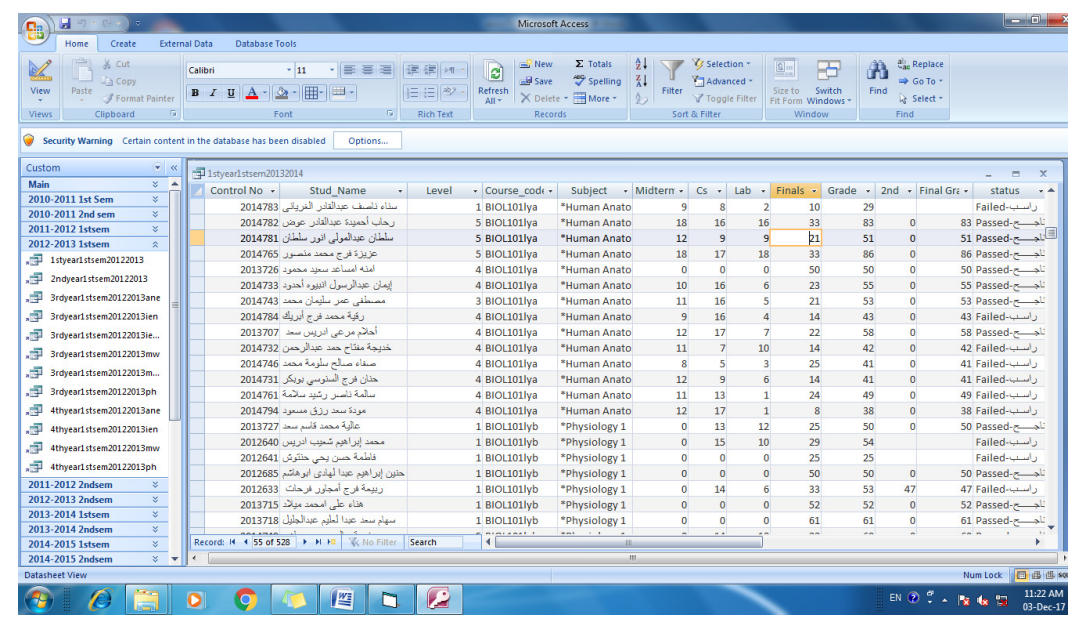

Figure 15: Datasheet View of OMUCON-GSv1 and TUCON-GSv2

Since TUCON-GSv2 is an update of OMUCON-GSv1, they are using the same database or back end. All records from the previous system and the current generated records were in the same repository table, separated via query per year level and department, grouped according to school year and semester. In figure 15 listed the datasheet view of the query for $1^{\text {st }}$ year $1^{\text {st }}$ semester 2013-2014. The fields for user input includes students control no, student name, level, course code, subject/course, midterm exam, class standing, laboratory, final exam, grade, $2^{\text {nd }}$, final grade and status. All student performance will be added to form the grade and will be generated as $1^{\text {st }}$ assessment report. Blank final exam (Finals field) will be reported as absent. If the student passed (Grade Field) it will be their Final Grade, if the student took $2^{\text {nd }}$ assessment it will be encoded in the $2^{\text {nd }}$ field and it will be their new Final Grade if the subject is purely lecture. If the course is with laboratory, it will add the lab mark (20\%) and the $2^{\text {nd }}$ exam (80\%) to from a new final grade. Status will be either passed or failed. 
International Journal of Database Management Systems ( IJDMS ) Vol.9, No.6, December 2017

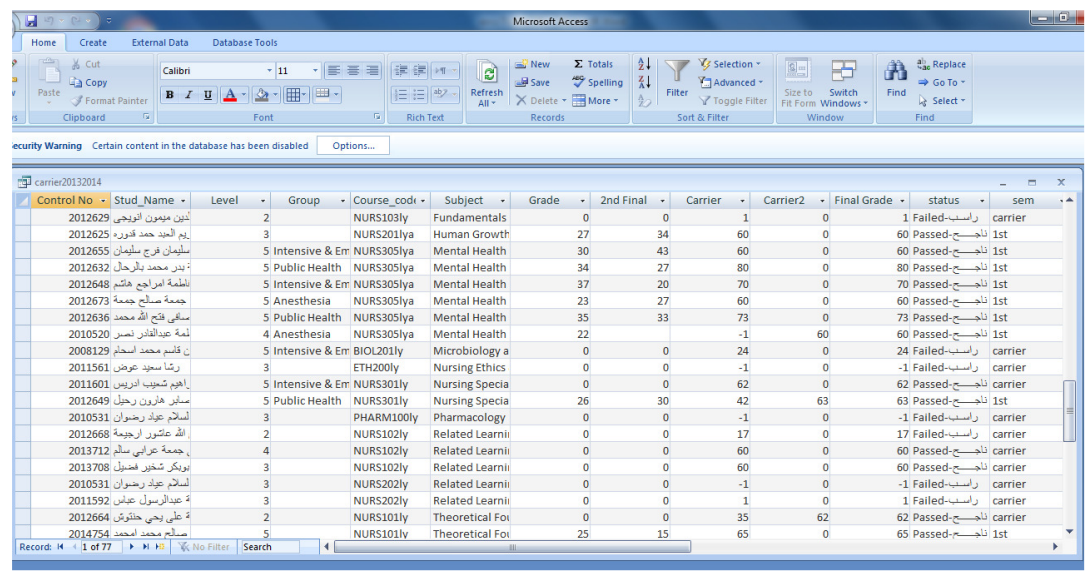

Figure 16: Datasheet View of OMUCON-GSv1 and TUCON-GSv2 of students with carrier

Some students who failed one or two subjects were given the privilege to be promoted to the next year level. The subjects they fail will be carried the following school year, students with carrier will be in a query were grade and $2^{\text {nd }}$ final grade were already listed from the previous year. There are two carrier repository; Carrier for $1^{\text {st }}$ take and Carrier 2 for $2^{\text {nd }}$ assessment if the student still fails the $1^{\text {st }}$ carrier exam. The last exam they took will be their Final Grade, if they still fail even the $2^{\text {nd }}$ carrier exam, the course will be listed as carrier the next school year provided they did not fail more than two subjects including the carrier course.

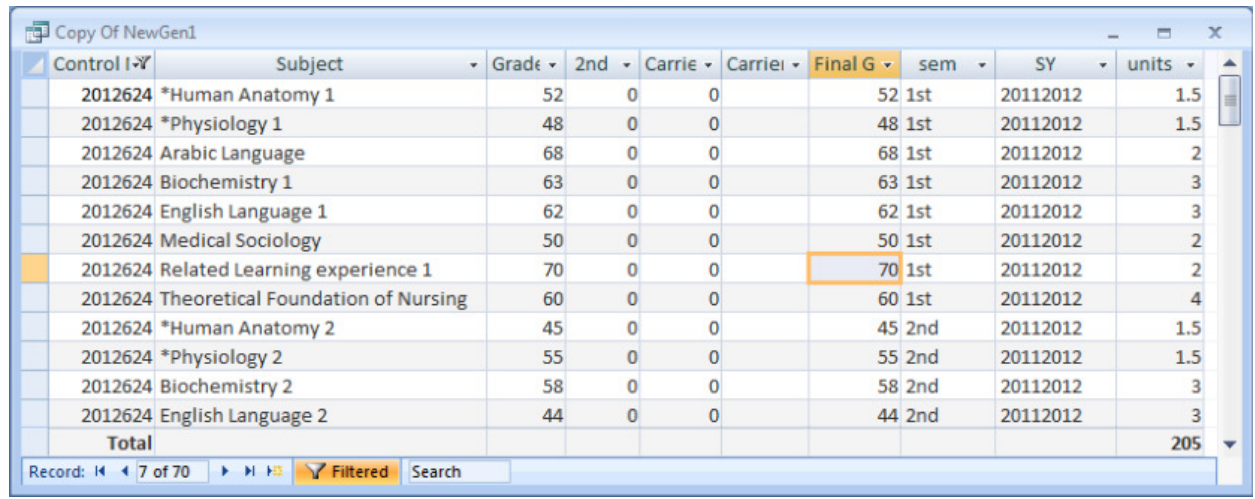

Figure 17: Datasheet View of OMUCON-GSv1 and TUCON-GSv2 of a searched student

Sorting and organizing of records using the same database file prompted the author to use the Microsoft Access as back end. It is also easier to use compared to other database system. Searching students by their control number especially if the operator is a non-Arabic speaking person. Sorting and searching of records were easier in this database compared if the records are all in a spreadsheet. 
International Journal of Database Management Systems ( IJDMS ) Vol.9, No.6, December 2017

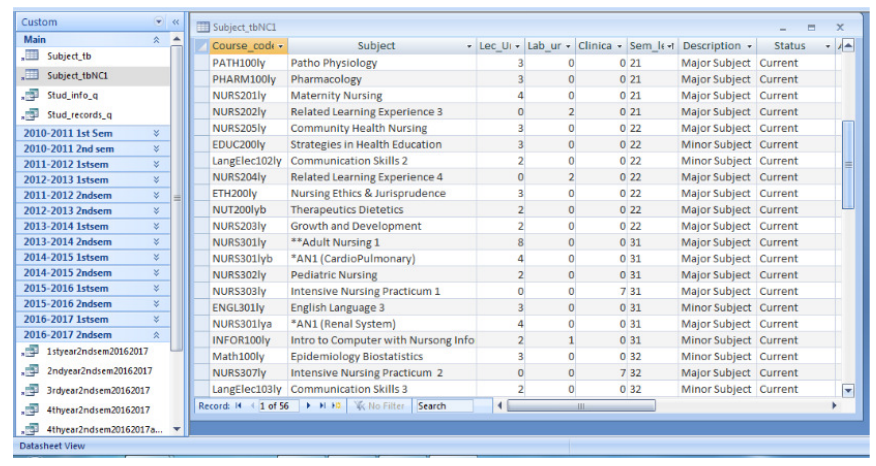

Figure 18: Datasheet View of current courses offered for TUCON-GSv2

Main records were grouped into 3 tables, Stud_records, Stud_info and Subject_tb. Stud_info list the student's information using a unique field control_no, other info like name, year level, department, check box if they are a current student or if they were a graduate already. In the database if the student's year level is 5 , it means they finished the whole program already. They were only shown here for record retrieval example. In figure 18 the table for Subject_tb were shown listing the course code, name of the subjects/course, Lecture units, laboratory Units, Clinical Units (for INP, hospital duty), Year and Semester offered (31 means, $3^{\text {rd }}$ year $1^{\text {st }}$ semester, 22 means $2^{\text {nd }}$ year $2^{\text {nd }}$ semester), Description if the subject is major or minor (general course) and Status if the subject is currently offered or the subject was discarded from the program.

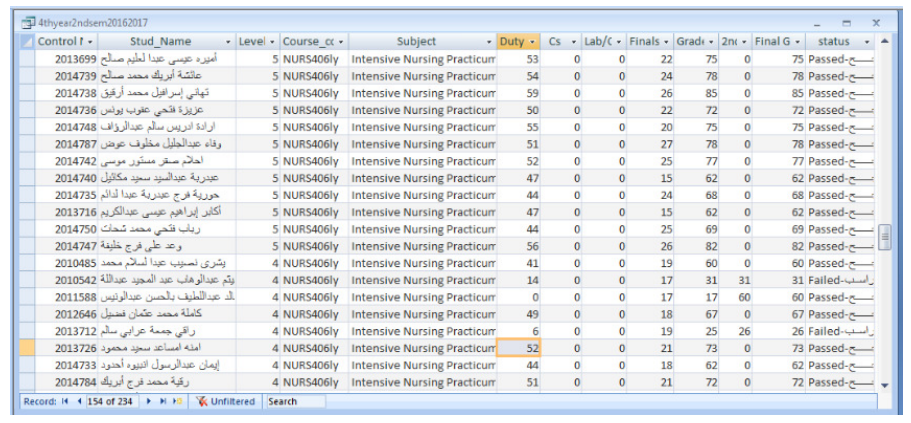

Figure 19: Datasheet View of $4^{\text {th }}$ year students of $2^{\text {nd }}$ semester school year 2016-2017 from TUCONGSv2

At the commencement of Libyan Civil war in 2011 the school attendance was postponed, to catch up with the school calendar after the war, the length of the semester was shortened from the regular 16 weeks down to 10 weeks. Even when the semester length was adjusted it was still only at 12 weeks or so. The University decided to remove the midterm exam for Colleges offering semester programs so there will be only one major exam, the final exam. The equivalent percentage for midterm and final exam were combined as the new final exam mark.

\subsection{Maintenance and System Upgrade}

To maintain smooth system performance, periodical maintenance and system upgrade together with several tests was performed. To ensure data integrity collaboration with clinical instructors and several authorities were performed. Most changes occurred when the curriculum was changed but was easily adjusted to fit the current program through the help of clinical instructors. The TUCON-GSv2 being the latest version had withstood the test of time. Holding 
more than 32 thousand records and transaction, the system remained steadfast. Main database were stored in the registrar's office and a backup copy were periodically placed in a flash drive.

\subsection{Data Mining Research}

In 2014 partial records of then OMUCON-GSv1 were used as a study population for a Data Mining research by the authors. Recorded data were helpful in educational data mining as unknown and hidden data patterns of all courses. Specifically records from Nursing Informatics course were used as a predictor for student's overall academic performance. Records were extracted and analyzed using the same database grading system now known as TUCON-GSv2. Introductory database management system methods and implementations like tables, queries, report, and pivot were used to present data, the system and the research generated valuable findings and performed according to needs. The system lived up to its expectation in storage and retrieval of data. Mining elements including extraction, analysis and presentation were performed and simplified by using query, filtering, pivot table and pivot chart. [7]

Generally the TUCON-GSv2 as it is now can generate helpful and meaningful data as it promoted simple educational data mining. The system serves as a vital element in the improvement of quality education for the College of Nursing in Tobruk University, Libya.

\section{REPORT GENERATION of TUCON-GSv2}

The main requirement of the Tobruk University College of Nursing administration is that the new system would generate the same tabular format they have from the old system (Figure 2). The format of the report must be retained to accommodate the request. Using the new database for recording of data and then calling a procedure to generate the same database in spreadsheet format becomes the solution.

The example code below (Source Code 1) was used to call and open Microsoft Excel and displaying it in the appropriate worksheet with a pre-made template for every year level and department selected in the main menu (shown on Figure 8).

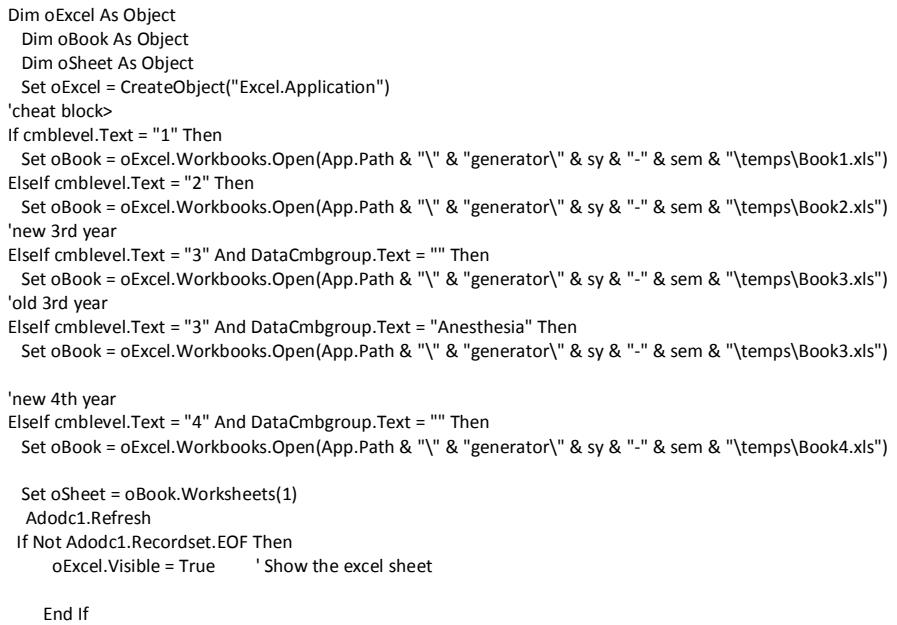

The number of subjects per semester is less than 10, since all course subjects will be displayed in column, selected fields from the database will also be the columnar title. Number of units was also concatenated to the subject in column field hence the use of trim command in VB. The 
International Journal of Database Management Systems ( IJDMS ) Vol.9, No.6, December 2017

code below (Source Code 2) also displays in the report title based on selected school year level and semester.

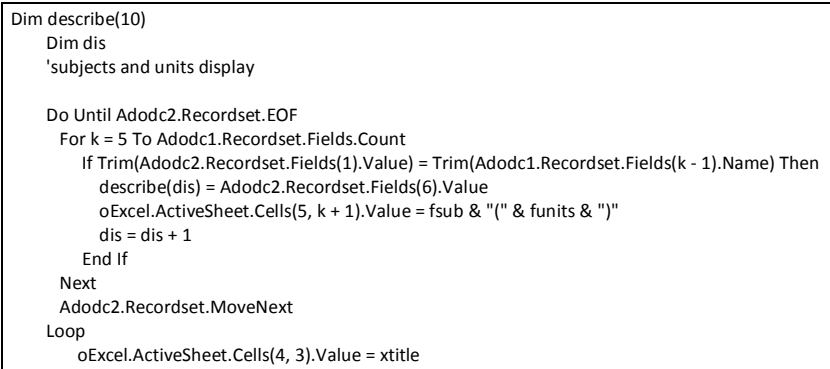

Source Code (2)

The number of student for every page of worksheet was set to 15 , it will be displayed using the same file so loop command was added to aid copying the cell template. Every page must have title and logo so the College logo was also duplicated in every page. (Source Code 3 )

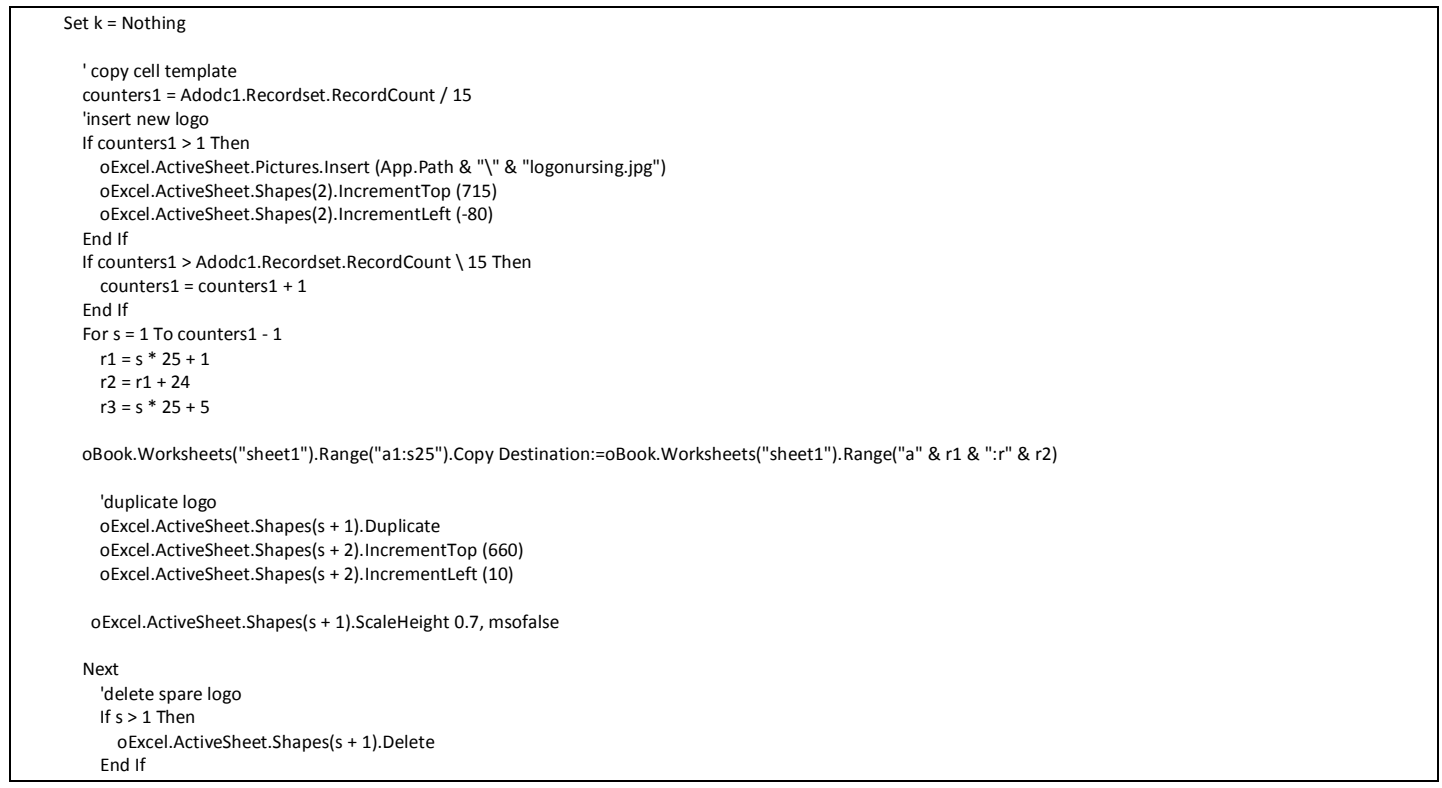

The students mark was displayed in tabular format; since students' grade was displayed as a group instead of individual marks the code below was used. In most instances the number of subjects is less than 10 so unused columns must be hidden, the number of students is not always divisible by 15 so succeeding unused rows must also be hidden. To protect the new worksheet from any alteration the sheet was locked after generation of report. (Source Code 4)

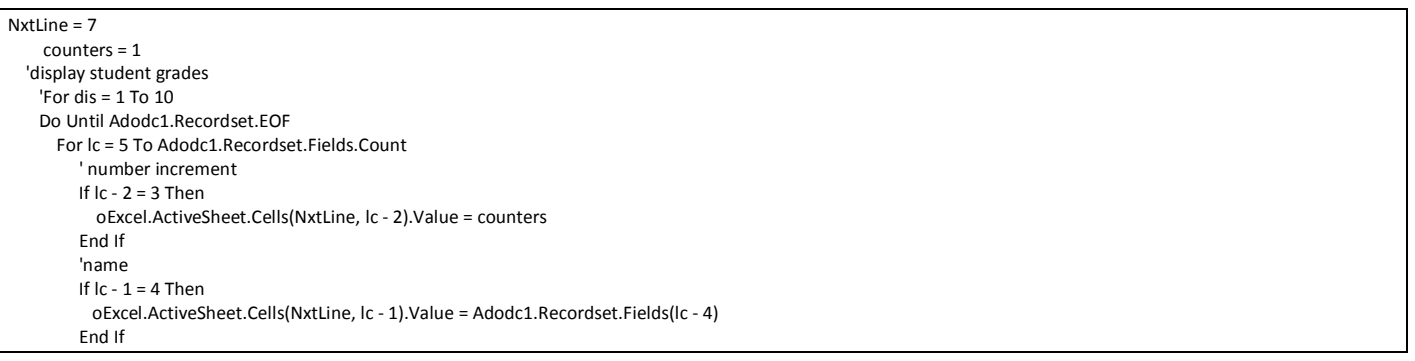


International Journal of Database Management Systems ( IJDMS ) Vol.9, No.6, December 2017

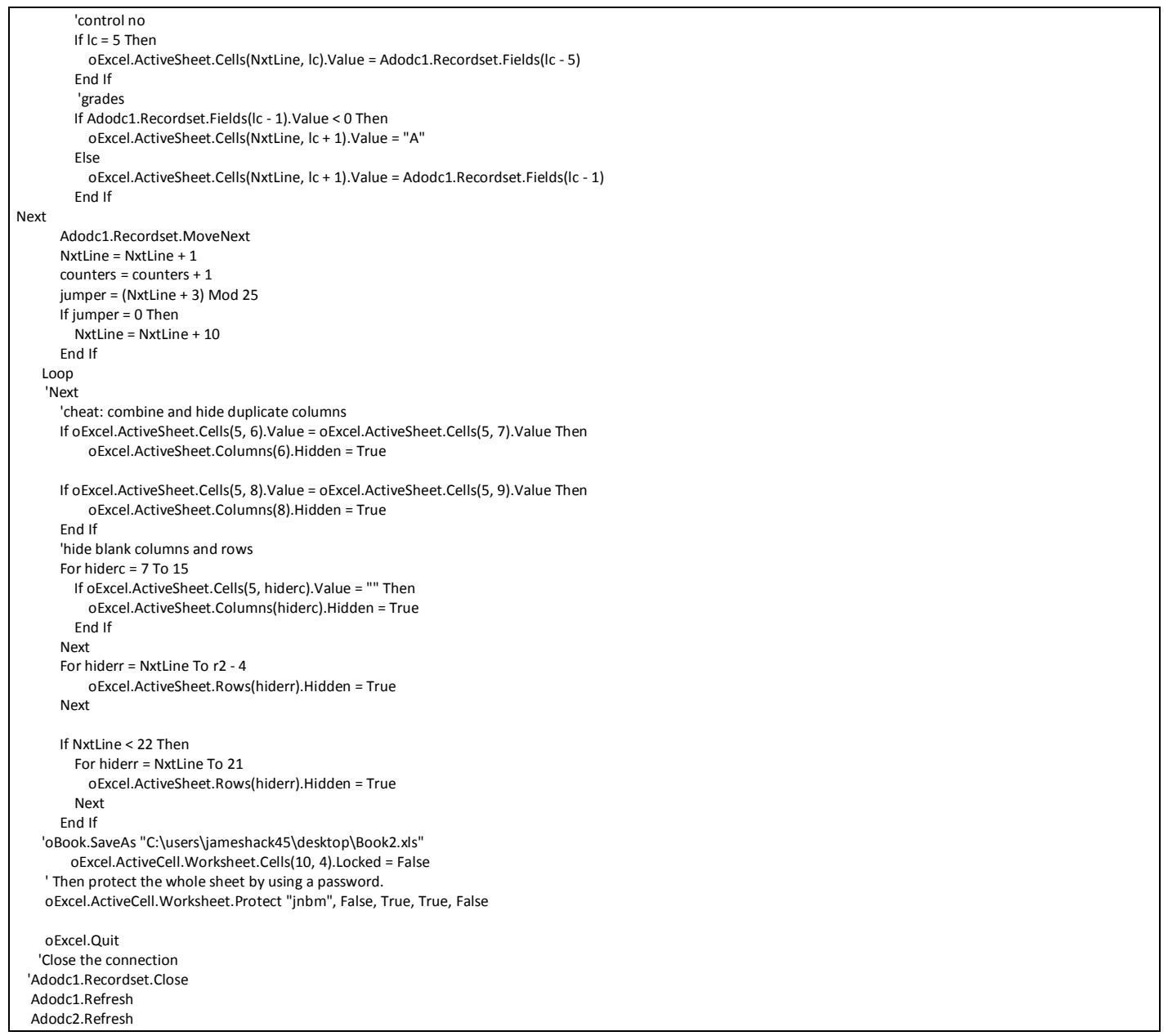

Source Code (4)

The following code (Source Code 5) was part of a sub procedure of print command; the code labels the school year level and semester of the generated query.

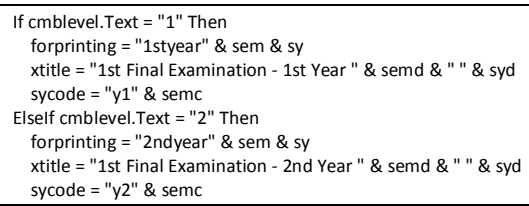

Source Code (5)

Finally an SQL code was needed to select the fields to display in the data control and the report generated in the worksheet. (Source Code 6)

SELECT stud info.[Control No], stud_info.Stud_Name, stud_info.Level, stud records.Course code, Subject_tb.Subject, stud records.Midterm, stud_records.Lab, stud_records.Finals, IIf([lab_units]>0,[Midterm]+[Lab]+[finals],[midterm]+[finals]) AS Grade, stud_records.[2nd] IIf $([2$ nd $]=0,[$ grade], IIf([lab_units] $>0,[2$ nd] $]+[$ lab], [2nd])) AS [Final Grade], IIf(([Final grade] $>=50$ And ([description]='Minor Subject') Or [final grade] $>=50$ And [description]=") Or ([grade]>=60 And [description]='Major Subject'),'Passed','Failed') AS status, stud_info.[List No]

FROM (stud_info INNER JOIN stud_records ON stud_info.[Control No] = stud_records. [Control No]) INNER JOIN Subject_tb ON stud_records.Course_code = Subject_tb.Course_code where (((stud_records.code)="' \& sycode \& "')And ((stud_records.sy)="'" \& sy \& "') And ((stud_records.sem) $=$ '" \& semcode \& "''))" 
International Journal of Database Management Systems ( IJDMS ) Vol.9, No.6, December 2017

Select statement was used to choose the fields to be displayed in the report. Computation for [Grade], [2nd] and Final Grade and determining if the subject is a major or minor course is also included.

Inner Join statement was used to combine the appropriate tables and was arrange by an Order By clause based on students [level], [subject] and [List No] to sort in ascending order.

\section{CONCLUSION}

Tobruk University College of Nursing Grading System version 2 performed generally well as a Database System for the College. Having the system eases up encoding, collecting of records, organizing and sorting for data retrieval, and report generation. The system is unique in its design as the reports were retained from the old system but recording was in the new database system instead. The study presented the operational aspects of the College of Nursing in Tobruk University in terms of grading of nursing students together with the use of TUCON-GSv2 and history of its predecessors using actual archived reports. Portion of the actual source code was also presented to address the report generation requirement of the College. The system promotes not only the use of Database Management system and data mining but promotes the whole Nursing program in Tobruk University as well, being one of the few Colleges using a systematic record handling of data in Libyan Universities. The TUCON-GSv2 can also generate useful data and turn it to a meaningful one to promote educational data mining and improving quality education.

\section{REFERENCES}

[1] Intravaia S, "Il liceale con la media del 9,93 "Sonoilpiù bravo d'Italia"", repubblica.it (in Italian), November 2009.

[2] http://dictionary.reference.com/browse/grade point average, Grade Point Average. (n.d.)., October 2011

[3] Dela-Cruz RA, Guido RM. Factors Affecting Performance of BS Astronmy Technology Students. International Journal of Engineering Research \& Technology 2013; 2(12):84-94.

[4] Friedman BA, Mandel RG. The Prediction of College Student Academic Performance \& Retention: Application of Expectancy \& Goal Setting Theories. Journal of College Student Retention: Research, Theory \& Practice 2009-2010; 11(2):227-246.

[5] Shovon HI, Haque M. Prediction of Student Academic Performance by an Application of K-Means Clustering Algorithm. International Journal of Advance Research in Computer Science \& Software Engineering 2012; 2(7):353-5.

[6] Grading Systems by Country,Libya,https://en.wikipedia.org/wiki/Grading_systems_by_country

[7] Mendoza JNB, Buhat-Mendoza DG, Libyan Students' Academic Performance and Ranking in Nursing Informatics -Data Mining for Starter's, International Journal of Database Management Systems ( IJDMS ) Vol.6, No.5, October 2014

[8] Robinson G, Use Access 2007 to get Started in Data Mining, www.databasejournal.com, 2009.

[9] Prasadi GNR, Babu AV. Mining Previous Marks Data to Predict Students Performance in their Final Year Examinations. International Journal of Engineering Research \& Technology 2013; 2(2):1-4.

[10] Roger AE, Ghislain AA, Joel SM. Migration of Legacy Information System based on Business Process Theory. International Journal of Computer Applications 2011; 33(2):27-34.

[11] Erdogan SZ, Timor M. A Data Mining Application in a Student Database. Journal of Aeronautics \& Space Technologies 2005; 2(2):53-7.

[12] Singh SP, Sharma NK, Sharma BK. Use of Clustering to Improve the Standard of Education System. International Journal of Applied Information Systems 2012; 1(5):16-20.

[13] Pandey UK, Bhardwaj BK, Pal S, Rajasthan PBJ. Data Mining as a Torch Bearer in Education Sector. Technical Jaurnal of LBSIMDS; 115-125.

[14] Establishment of the University of Tobruk,https://www.theuot.com/الجامعة-عن-نبذة/الرئيسية//,, (in Arabic)

[15] Gupta S, 4GT in Software Engineering http://shivgblog.blogspot.com/2015/03/4th-generationtechniques-in-software.html, March 2015. 
International Journal of Database Management Systems ( IJDMS ) Vol.9, No.6, December 2017

\section{ACKNOWLEDGEMENT / SOURCE OF SUPPORT}

The authors would like to thank first and foremost God Almighty for the grace and glory of His name, giving us the gift of wisdom and inspiration to write this study. We acknowledge our family specially our mothers and also our friends, for their unwavering support. And to the publisher for the insight in promoting research development, thank you and God bless us all. 